\title{
POSSIBILITIES OF ENERGY HARVESTING FROM THE SUSPENSION SYSTEM OF THE INTERNAL COMBUSTION ENGINE IN A VEHICLE
}

\author{
Jacek Caban ${ }^{1 * *}$, Grzegorz Litak${ }^{1}$, Bartłomiej Ambrożkiewicz ${ }^{1}$, Leszek Gardyński², Paweł Stączek ${ }^{1}$, Piotr Wolszczak $^{1}$ \\ ${ }^{1}$ Department of Automation, Faculty of Mechanical Engineering, Lublin University of Technology, Lublin, Poland \\ ${ }^{2}$ Department of Materials Engineering, Faculty of Mechanical Engineering, Lublin University of Technology, Lublin, Poland \\ *E-mail of corresponding author: j.caban@pollub.pl
}

\section{Resume}

The automotive industry faces huge challenge in environmental protection by reducing fossil fuels and energy consumption by developing various practical solutions in energy harvesting. The current analysis is related to the diesel engine power supply system in a passenger off-road vehicle for application of the piezoelectric energy harvesting system. Experimental tests were carried out for the three constant rotational speed values - 800, 1000 and $1500 \mathrm{rpm}$. The results pertained to operational and simulation tests of available power supply options from the engine suspension system in the vehicle, e.g. to power sensors supervising the engine's operation or other small electrical devices in the vehicle. The simulations of output voltage were conducted by means of a nonlinear model with a resonator coupled to a piezoelectric elastic beam deformed in the magnetic field to improve the band of frequency transducing kinetic mechanic energy into electric energy.

Available online: https://doi.org/10.26552/com.C.2021.2.B106-B116

\section{Article info}

Received 20 July 2020

Accepted 17 August 2020

Online 26 January 2021

\section{Keywords:}

diesel engine, energy harvesting, terrain vehicle, duffing oscillator
ISSN 1335-4205 (print version)

ISSN 2585-7878 (online version)

\section{Introduction}

Pollution of the environment, repletion of natural supplies and growth in the volume of waste disturb the equilibrium of the natural environment [1]. In addition, the constantly increasing demand for energy and continuous technical development lead to the search for new solutions in use and recovery of energy from various technical systems. This pursuit occurs in numerous sectors of the economy and various technical facilities. Transportation, which is one of the most important parts of development, also contributes to environmental issues and energy waste [2]. Currently, we are witnessing a huge transformation in the transport and automotive industry. In the automotive industry, one can see enormous progress in development of the new propulsion systems (electric and hybrid) and in improvement of piston internal combustion engines with both spark ignition [3-5] and compression ignition engines [6-7]. Development of fuels alternative to crude oil has become another area. There is an increasing interest in the fuels of vegetable origin (bio-diesel) [1, 8] gas fuels from biogas plants and other, e.g. LPG, CNG [9-10].

As far as internal combustion engines are concerned, development of the fuel supply systems, exhaust purification systems and diagnostic systems has been particularly important. Recently, vibration signal analyses have been heavily used for diagnostic purposes of various engine assemblies and systems, as well as other vehicle systems, e.g. suspension or transmission. Many researchers use methods such as Fourier and Wavelet Transforms [11-14] and Hilbert Transform (HT) [15-16], Recurrence Plots [17], Neural Networks [18] in detecting defects and operational parameters in rotating systems. Authors of $[8,19]$ diagnosed the fuel supply systems using vibration signals are noteworthy. Balytskyi et al. [19] investigated degradation of the lock seal ring based upon the loss of combustion engine working gases. In [11, 20-21], authors used a vibration signal to analyze the technical conditions of gears. In [22-25], authors used analysis of the vibration signals to diagnose the vehicle suspension systems.

Reducing vehicle energy losses is necessary in order to improve fuel economy, reduce emissions, and supply other systems' power demand [9, 26-28]. In addition to improving engine and powertrain efficiency, one may also harvest energy wasted in vehicles including the recovery of wasted heat energy [24, 29], regenerative braking energy [30] and vibrational energy of shock absorbers [25, 31]. As demonstrated by Abdelkareem et al. [25], an average power of $350 \mathrm{~W}$ can be obtained from a medium-sized sedan (using four energy-harvesting dampers) from vehicle vibration stimulated by road irregularities. For larger vehicles the harvestable power can be greater. 


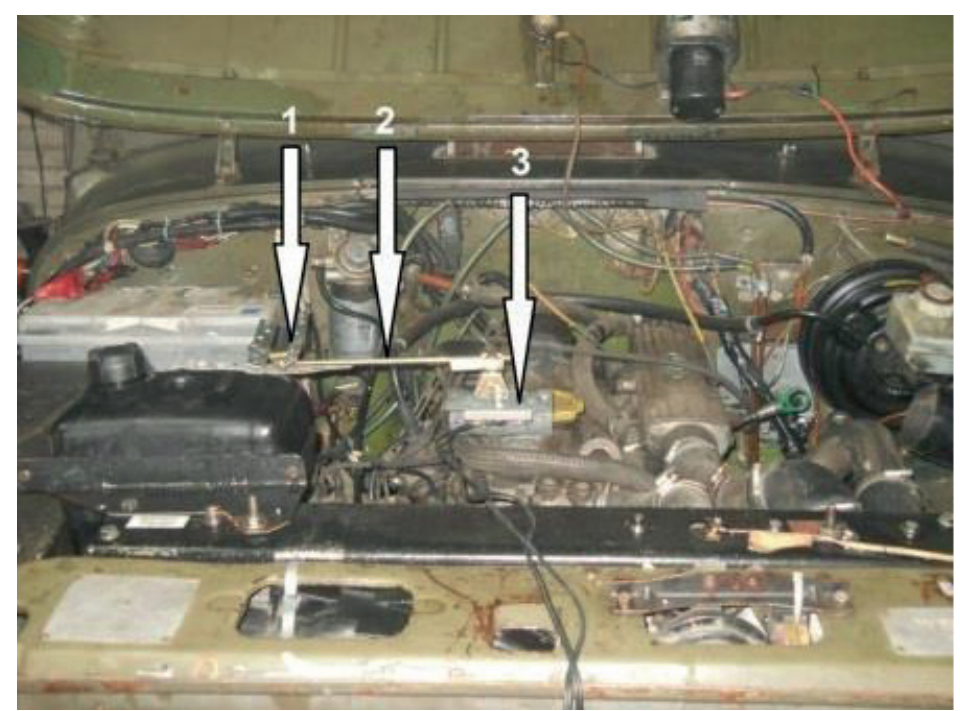

Figure 1 The way of mounting the measurement system in the tested vehicle,

1 - suspension structure of the clamping arm, 2 - potentiometer arm, 3 - linear potentiometer

Energy recovery in the sector of transportation has become an interesting and increasingly undertaken research topic. Obtaining energy from roads as an innovative way to provide green and renewable energy for the needs of sustainable transport is one of the directions [22]. Technologies, which harvest energy from roadways include piezoelectric-based modules [23, 32], asphalt solar collectors [33], thermoelectric systems [34], electromagnetic systems [35] and the solar panels installed in the pavement [36]. Another direction of research is harvesting energy from various components of a vehicle and the internal combustion engine. In this way, previously lost energy can be used to power certain on-board devices or electrical sensors supervising various functions in the vehicle.

The vibration-based energy conversion, termed piezoelectric energy harvesting, has significant advantages when compared to other forms of renewable energy, including the low start-up investment and less complex wiring [37]. The piezoelectric energy harvesting has been identified as a candidate for low-power devices such as portable rechargeable devices [38], wireless electronic devices [39] and sensors [40]. In the considered case, the nonlinear bi-stable resonator with a piezoelectric elastic beam is used. The bi-stable system provides broadband frequency transduction [41-44].

Unlike the small-scale energy-harvesting, such as wireless sensors and electronic devices, systems based on energy harvested from a vehicle's combustion engine suspension have not been sufficiently investigated. However, there is a space to partially recover energy from the suspension system of the internal combustion engine of a vehicle during its operation. This option was tested for aircraft vibrations in multimodal transport [45]. For this purpose, exploratory tests, based on measurements of vibration and displacement of the diesel engine during its operation, were carried out at three different crankshaft rotational speeds (800, 1000 and $1500 \mathrm{rpm})$.

In this article the focus is on application of the experimental data as the excitation for the piezoelectric energy harvesting system based on the Duffing oscillator. The remainder of this article is following. In the Section 2 , the experimental procedure is described, i.e. the experimental setup, the duty cycle and the measuring circuit. In the Section 3, the information is provided on the bi-stability phenomena, proposed piezoelectric EH system and broadband effect. Next, the output results from simulations, after applying the experimental time series to the mathematical model, are shown. Section 5 summarizes the paper.

\section{Materials and Methods}

The engine suspension study was conducted on a running diesel engine at selected values of the crankshaft rotational speed (800, 1000 and $1500 \mathrm{rpm}$ ) as the most frequently obtained speeds during the standard operation of a vehicle. The subject of the research was the following: a passenger all-terrain vehicle UAZ-31512 (earlier 469B type) with a four-cylinder supercharged diesel engine 2.5TD with direct injection used in Land Rover Discovery vehicles 200 series.

Despite the green revolution in automotive industry and more and more often application of alternative driving systems, the Diesel engine is still widely used in transportation, industry, agriculture and construction, owing to their high efficiency, reliability and durability [46]. The reason of application of the Diesel engine car in the experiment are relatively high amplitudes of vibrations generated by engine comparing to the gasoline engine [47] and possibility to use the terrain vehicle in off-road having additional natural external source of mechanical vibrations. Nevertheless, the engine operation by different rotational velocities will bring diversified response of energy harvesting system. The tests were carried out for the three rotational speeds on an engine warmed up to 


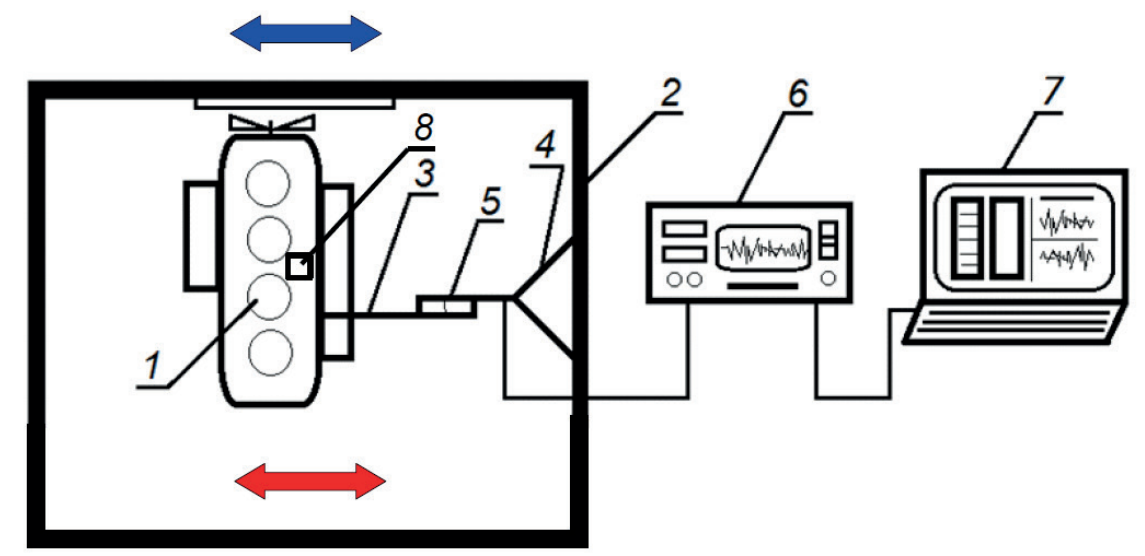

Figure 2 Scheme of the measurement system in a tested vehicle, 1 - diesel engine, 2 - vehicle body, 3 - potentiometer arm, 4 - load-bearing structure, 5 - linear potentiometer, 6 - oscilloscope, 7 -computer, 8 - energy harvesting system, the proposed energy harvester is going to be attached to the engine housing, red arrow denotes horizontal excitation of engine, blue arrow denotes the excitation of a vehicle during the driving

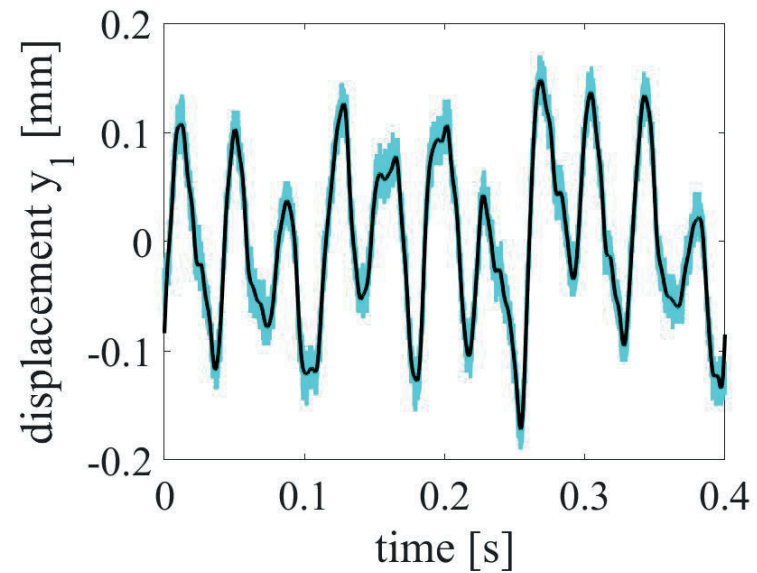

a)

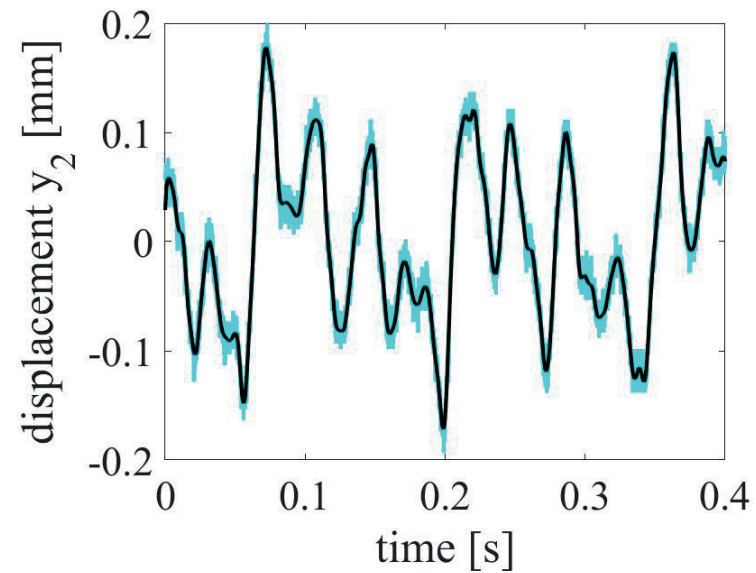

b)

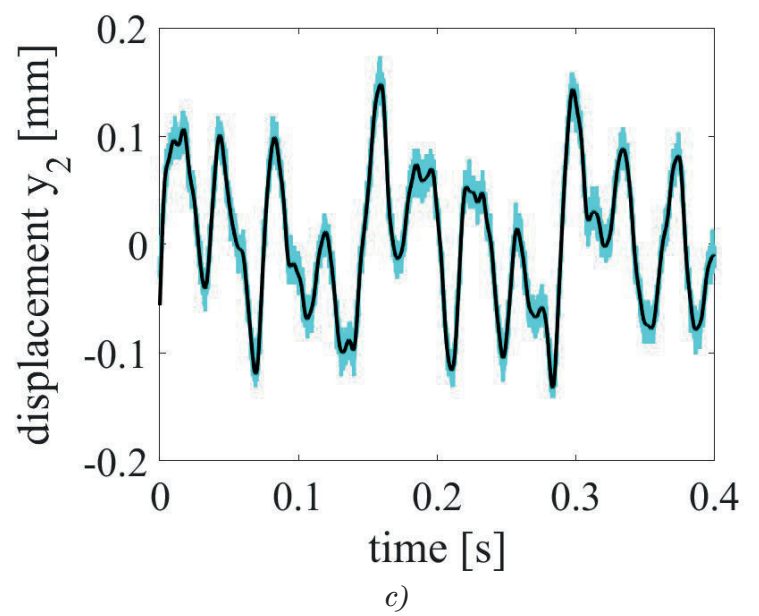

Figure 3 Displacement time series obtained from engine vibrations during driving, three different driving modes $n=\{800$; $1000 ; 1500\}[\mathrm{rpm}]$ are considered for (a),(b), and (c) respectively, the acceleration was also measured in voltage, but it is scaled for the accelerometer purpose, note: cyan color denotes the original measurement series and black line the corresponding data after application of the low pass filter with the frequency window below $170 \mathrm{rad} \cdot \mathrm{s}^{-1}$

a normal operating temperature. The way of mounting the measurement system in the engine chamber of the tested vehicle is presented in Figure 1.

The engine's displacement was measured using a specially constructed arm with a potentiometer which transformed it into voltage and transferred the value to the oscilloscope DSO-2902 256K. The potentiometer transducer was A-linear type with $22 \mathrm{k} \Omega$ resistance and $0.5 \%$ linear tolerance. The diagram of the measurement trajectory of engine-to-body displacement is presented in Figure 2. 


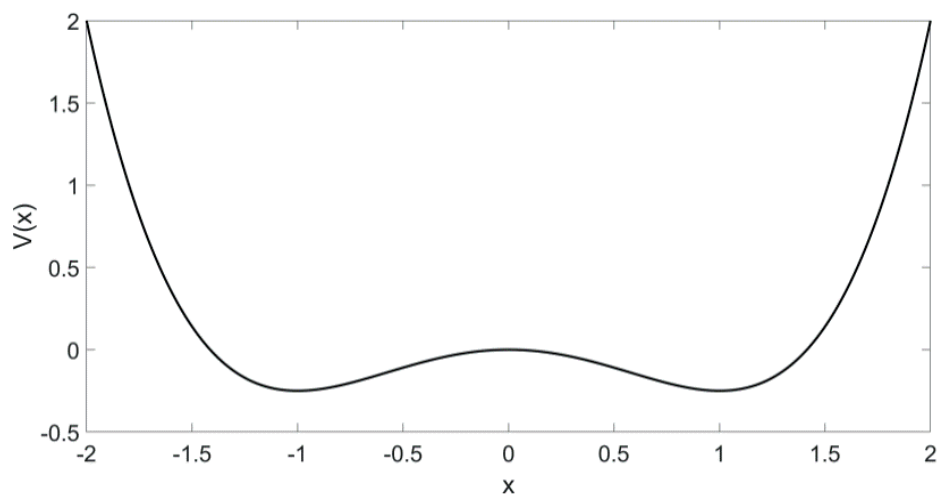

Figure 4 Potential energy $V(x)$ of the system in the Duffing oscillator versus displacement, three equilibrium points creates double-potential well, which is consisting of $x=-1,1$ for stable and 0 for unstable equilibria (dimensionless model)

The device scale was selected in such a way that the voltage value corresponded to the appropriate displacement value $(1 \mathrm{~V}=1.6 \mathrm{~mm})$.

Tests measurements of acceleration in the suspension system were performed by means of the experimental setup (Figure 2). The displacement results of the measurements are presented in Figure 3 using the cyan color. In the next sections an energy harvesting system to transform the kinetic inertial excitation energy into electric power is proposed.

Unfortunately, this data is strongly affected by the measurement noise. Therefore, the initial digital signal processing of the experimental signals using the low pass filter is performed (see black curves in Figure 3). These time series are then applied as the source of excitation in the model. The outcomes of the simulation in form of inertial force courses, phase portraits, voltage response are presented in the next sections.

\section{The bi-stable energy harvester based on Duffing oscillator}

A greater focus is placed on the non-linear behavior in vibratory energy harvesting (VEH) systems and more attention is paid to the bi-stability phenomenon. Such systems are characterized by double-well potential, in which the tested system can get stuck in one of the two equilibrium points with small amplitude oscillations. Alternatively, it can oscillate with a large amplitude going through the potential barrier. One of the main advantages of this type of energy harvesters is the possibility of improving their performance by adjusting the operational frequency to desirable effect in the form of operational frequency or output voltage/power [41]. The design of the proposed system can represent three types of operating modes, i.e. single-well (intra-well) mode, when the system has the tendency to be stuck in one of the wells, chaotic doublewell (inter-well) mode or periodic double-well depending on the excitation [46]. However, the strongest effort is placed on the third mode where the system operates in the periodic double-well mode. This constitutes the most desirable behavior.
Stanton et al. [47] found the greatest strain profile nearest the equilibrium point obtaining the highest response. Masana et al. [48] showed the advantage of a bi-stable energy harvesting (EH) system over the mono-stable, superharmonics resonances in that it could activate the inter-well dynamics by even a small amplitude of excitation resulting in higher voltage response. Cottone et al. [49-50] proposed a design of a piezoelectric buckled bridge in which the highest voltage response is in the equilibrium point during the beam compression. In previous works by authors of this paper [51-57], the research focused on a different type of excitations acting on the system with the doublewell potential both in mathematical and experimental approaches.

In many studies of vibration energy harvesting mathematical models, the Duffing oscillator, characterized by the double-well potential, is applied. Its equation of motion describes the complex dynamics, but the cubic nonlinearity and properly selected perturbation coefficients bring an advantage in the form of hardening or softening response of the system. This results in wider range of operational frequencies. By combining the piezoelectric coupling with the Duffing oscillator, equation of motion and an addition of the Kirchhoff laws to the circuit with a resistive load, one obtains electromechanical equations describing the system dynamics [41]:

$$
\begin{aligned}
& \ddot{x}+2 \zeta \dot{x}-\frac{1}{2} x\left(1-x^{2}\right)-\chi v=F \cos (\omega t), \\
& \dot{v}+\lambda v+\kappa \dot{x}=0
\end{aligned}
$$

where $x$ is the dimensionless displacement of the beam in the transverse direction, $\zeta$ is the mechanical damping ratio, $\chi$ is the dimensionless piezoelectric coupling term in the mechanical equation, $v$ is the dimensionless voltage across the load resistance, $F$ is the dimensionless excitation force, $\omega$ is the dimensionless excitation frequency, $\lambda$ is the reciprocal of the dimensionless time constant, $\kappa$ is the dimensionless piezoelectric coupling term in the electrical circuit equation. Solution of Equation (1) gives three equilibrium points, saddle point $(x, \dot{x})=(0,0)$ and two $\operatorname{sinks}(x, \dot{x})=( \pm 1,0)$.

In the next section of this paper, with regard to the 


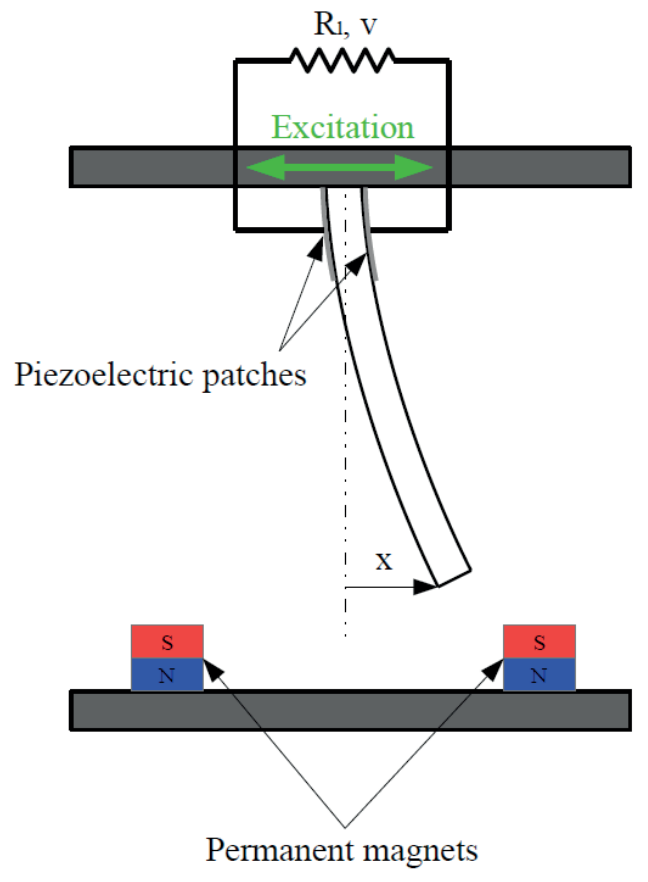

Figure 5 Model of piezoelectric energy harvester. Schematics of a beam with tip mass in form of permanent magnets

excitation of the bi-stable harvester (Figure 4 and Figure 5), application of the signal recorded on the frame of the diesel engine in the SUV vehicle is described. This is an acceleration signal to be considered as the input excitation for the energy harvesting system based on the Duffing oscillator. Energy harvesting systems, based on thermal transformations, have the highest efficiency in automotive. However, small portions of energy obtained from engine vibrations can support sensors placed in the engine such as the crankshaft sensor or oil temperature sensor. The oscillator response, excited with three different random signals, obtained from different road characteristics, is described in the following.

Advantage, coming from the bi-stability phenomena occurring in the system, is a broadband effect resulting in higher mean output power obtained in a wider range of operational frequency. In contrast to the linear system, which has only one specific value of frequency in the resonance region, the nonlinear bi-stable system is characterized by a broad frequency band composed of inclined resonances of one and multiple period responses (Figure 6). In calculations the initial conditions: the displacement was fixed to 1,0 (one of minima in the potential) while velocity was selected random for each frequency, and the initial voltage was nodal. Note that the single well linearized natural frequency is fixed to 1.0 (see Equation (1). These results were obtained using the random initial condition for velocity and 1 for displacement. Similar diagrams were discussed in [43-44, 52]. Note that the sub-harmonic responses with a large voltage output cover a large interval of excitation frequencies. These solutions correspond to the inter-well oscillations of the resonator. On the other hand, the small voltage response is related to the intra-well solutions. Those solutions include non-periodic solutions,

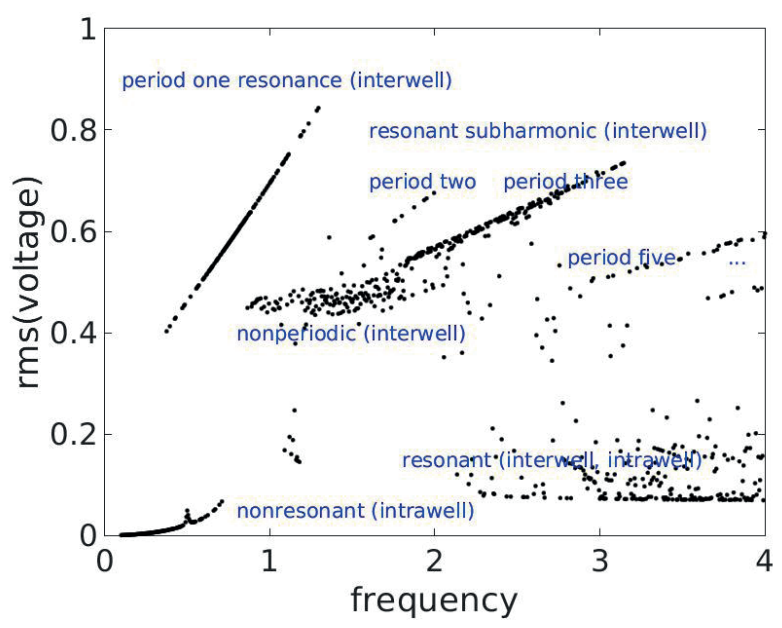

Figure 6 Voltage versus angular frequency showing a frequency (angular) broadband effect calculated from the model (Equations (1)-(2)). with the parameters $\zeta=0.01, \chi$ $=0.05, \lambda=0.01, \kappa=0.5, f=0.183$ attached to the moving

frame. The inertial force is acting on the elastic beam

which are also useful for energy harvesting. In such cases, the system passes through the potential barrier in a nonperiodic (chaotic) way.

Disadvantages of the bi-stable VEH proposal are based on appearance of multiple coexisting solutions, including the optimum solution, with questionable robustness in the presence of disturbances such as uncertainties in source and system parameters.

\section{System parameters and configuration of the energy harvesting system}

In this energy harvester design, attached to the engine suspension (Figure 1), one starts from the original equation

$m \ddot{z}+2 c \dot{z}-\frac{k}{2} z\left(1-z^{2}\right)-\chi^{\prime} V=F^{\prime}(\tau)$,

where, with respect to the model structure (Figure 5), $z$ is the displacement of the frame / oscillator / harvester, $m$ is an effective mass of the first mode beam motion, $c, k$ are effective damping and nonlinear stiffness coefficient, $V$ is the voltage output and $\chi^{\prime}$ is the coupling parameter, $F^{\prime}(\tau)$ is the inertial force $F^{\prime}=-m \ddot{y}$ is the kinematic excitation force governed by the engine relative displacement $y$. We transform this equation to the dimensionless by adjusting the parameters as follows: $k / m \beta^{2}=1$, where $\mathrm{k} / \mathrm{m}=\Omega^{2}, c=$ $\zeta / \beta$, where $\beta=\omega / \Omega, \Omega \tau=\omega t$, (to transform to dimensionless time into the band $\omega$ of [1-4] (see Figure 6)). Finally, the beam tip point $z$ and voltage $V$ will be changed to $x$ and $v$, with respect to the geometrical, material and electrical properties of the system (to fit Equations (1) and (2)).

The power generator is based on the ferromagnetic beam, two PZT-5A piezo-ceramic layers QP16N are attached 

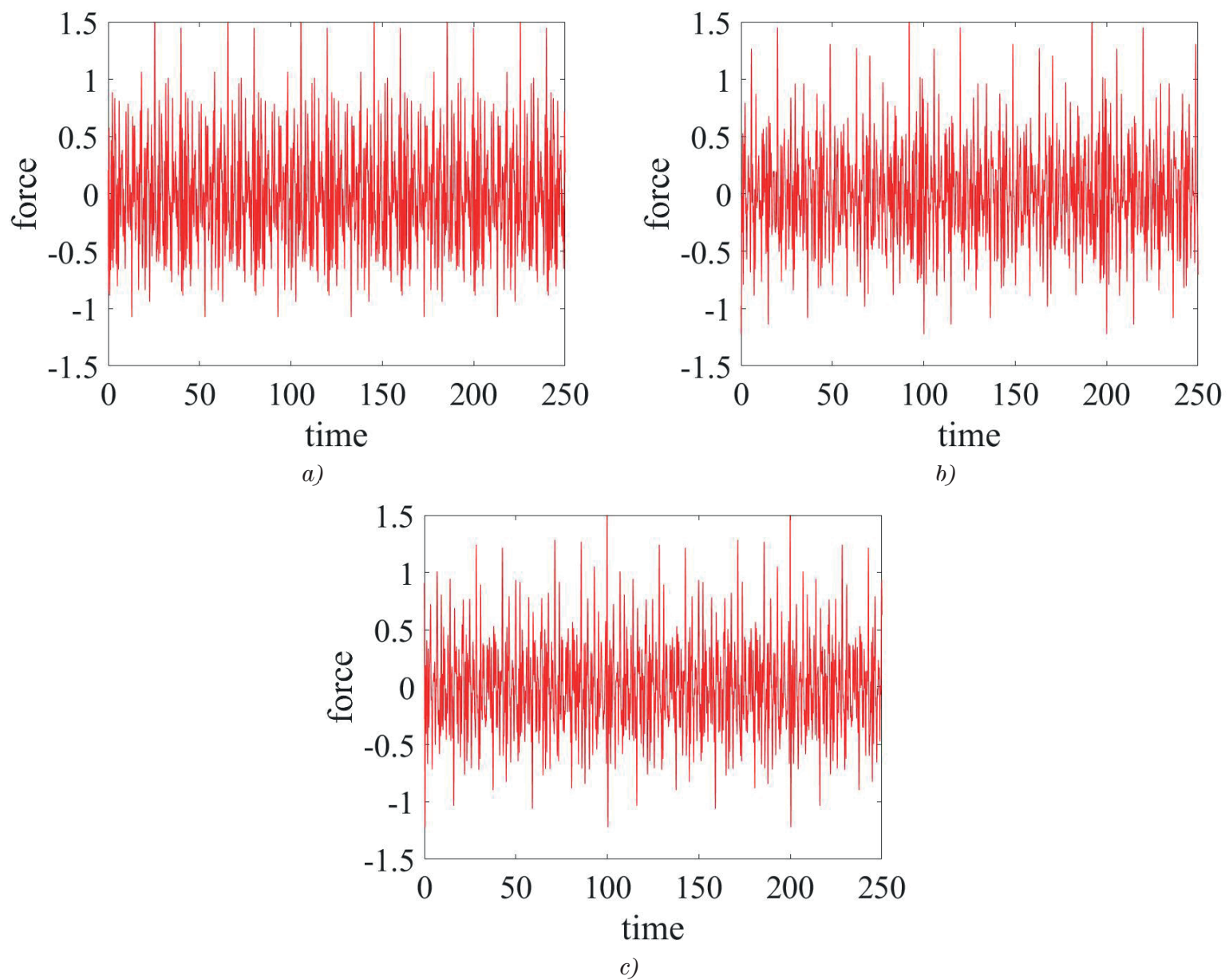

Figure 7 Inertial force time series from the experimental data (dimensionless model Equations (1)-(2)), the cases (a)-(c) have been estimated as the second order time derivatives of displacements in Figures $3(a)-(c)$, respectively and expressed in dimensionless units

onto both faces of the beam at the root using a high shear strength epoxy. The modulation of permanent magnets is adjustable in order to obtain bi-stable configuration of the system.

\section{$5 \quad$ Numerical simulations and results}

In this section are presented results of the numerical modelling of the proposed $\mathrm{EH}$ system excited with the signal coming from vibrations generated by a diesel engine during its operation. For the numerical simulations three rotational velocities of the crankshaft are taken to observe the change of the inertial force of the beam in the additional magnetic field, the output voltage response from the piezoelectric, with phase portraits instead. The behavior of the system is presented below.

The experimental signals were obtained by the three different rotational velocities, i.e. $n=\{800 ; 1000 ; 1500\}$ [rpm]. In order to obtain the response in the longer period of time, the signals were multiplied a few times still reflecting the engine operation under one specific rotational velocity. The applied Duffing oscillator works as the filter for the vibration signals. The perturbation parameters in its equation of motion and in the equation of electromechanical coupling are the following $\zeta=0.01$, $\chi=0.05, \lambda=0.01, \kappa=0.5$ (see Equations (1) and (2)). The external force, as presented in Figure 7, is substituted with experimental signals. For all the considered cases the initial conditions are the same at one of the stable equilibrium points $(x(0)=1)$ with the zero initial velocity and voltage.

Regarding the obtained time series of the inertial forceacceleration (Figure 7) it can be stated that the excited beam is getting lumped in the stable equilibrium points. Amplitudes of the inertial force in all the cases are almost the same varying in the frequency. The phase portraits (Figure 8) present the situation when the beam is changing its position from one well to another. As a consequence, the engine's vibrations are able to cause the chaotic movement of the beam by various rotational velocities. It is difficult to interpret the phase portraits at once. However, the output voltage time series of the piezoelectric element in all the cases present strongly non-periodic behavior of the beam. Both the characteristic jumps between the wells and oscillating response are observed in all cases. The highest $R M S(\mathrm{~V})$ response (Figure 9) was obtained for $n=800$ [rpm], but all the outputs were similar, namely, $0.25,0.18$ and 0.20 in cases (a-c) of Figure 9, respectively. Despite the similar values of obtained voltage response, the character of time courses differs for each case. In general, one has the multi- 


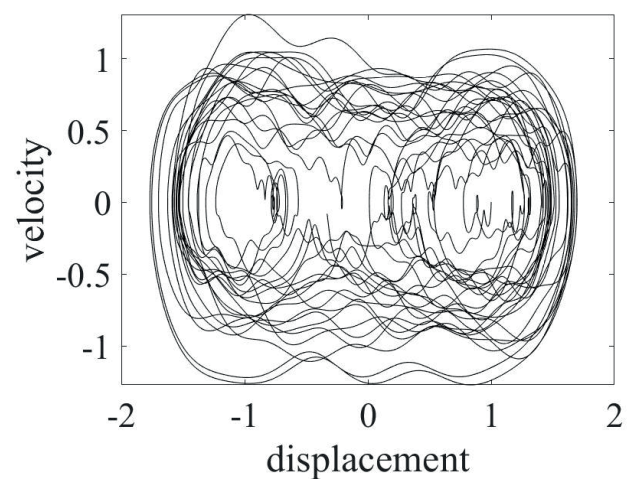

a)

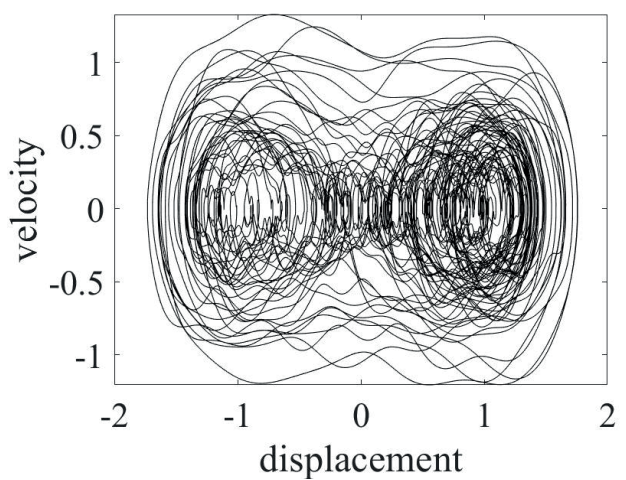

b)

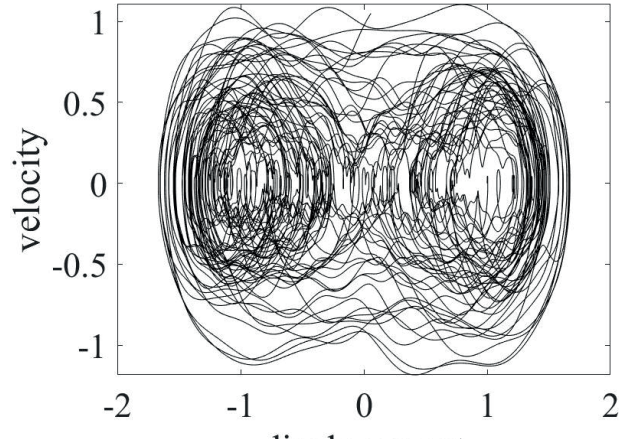

c)

displacement

Figure 8 Phase portraits of energy harvesting resonator response excited by the Diesel engine vibrations (dimensionless model)

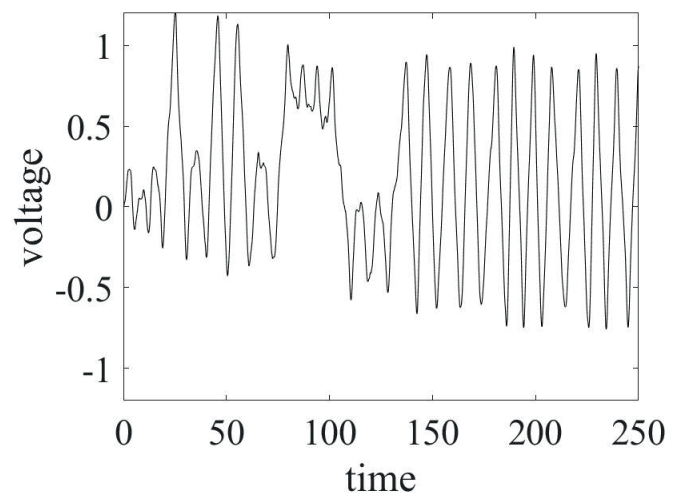

a)

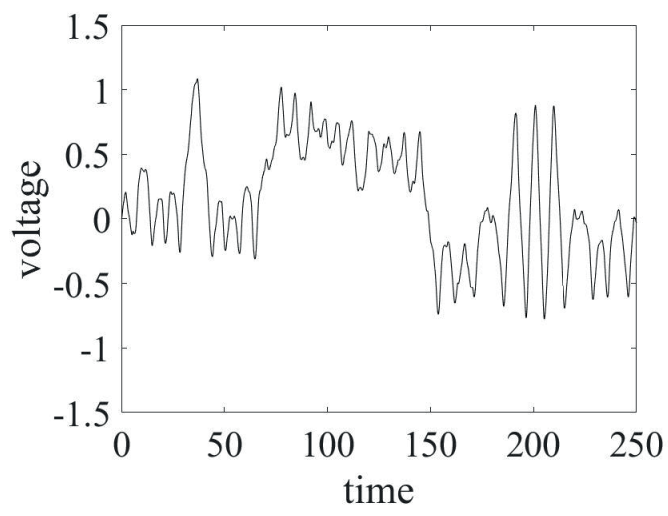

b)

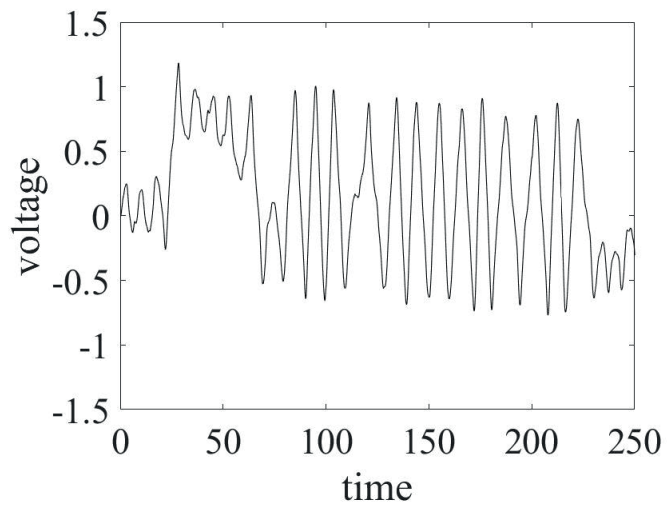

c)

Figure 9 Voltage response of the piezoelectric beam (dimensionless model). The corresponding root mean square of the voltage outputs, $R M S(V)$, were estimated as a) $0.24, b$ ) 0.18 and c) 0.20 , respectively 
frequency excitation and obtains the periodic response, when the ferromagnetic beam moves between the potential wells and time intervals of beam stuck in wells. The dimensionless model is proposed for the experimental excitation, but the energy system provides possibility to introduce changes in its design within dimensions of the beam and make the system's response adjustable to supply the connected sensor.

\section{Conclusions}

The main idea in development of the energy harvesting technologies is to apply own concepts in the real environment. In the present paper, application of a piezoelectric EH system, based on the Duffing oscillator in the diesel engine, is proposed. Random vibrations, generated by the engine, caused the movement of the beam with the tip magnet, by different operational velocities of the crankshaft and application of the nonlinear methods (phase portraits and resonance curve) allowed to observe its displacement between the two potential wells. The chaotic character of the beam movement and strong nonlinearity of the system in different duty cycles show the broadband effect in the system. This means that it can be applied in a wider range of operational frequencies than in the linear system. Simulations of the analytical model demonstrated that even the small magnitude of external excitation and proper initial conditions are able to provide the desirable inter-well behavior of the beam. The nonlinear EH system, based on the Duffing oscillator, can adapt to the different source of vibrations generated by the engine still gaining the energy, which can be possibly later used to power up the low self-powered diagnostics sensors mounted in the engine block. The next step in the research would be to build the prototype of the EH system and test it in the engine block by different duty cycles. Subsequently, the comparable results from the test and the mathematical model would lead to the nonlinear system's optimization in order to reach the maximum output power in the wide range.

Note that the general dimensionless model of the $\mathrm{EH}$ is proposed. To design the specific device one should re-examine the properties of the excitation sources (amplitude and frequency of excitation) and scale the size and mass of the resonator accordingly.

In general, not much difference in performance is found in terms of average induced voltage between the applied duty cycles in the experiment; however, this gives the idea to prepare the further research by changing the design of the $\mathrm{EH}$ system and perform extended experiment considering not only other rotational velocities but the variable road conditions, as well. The strongly nonlinear behavior of the system also gives another direction of research for applying methods for quantification of nonlinearities in the system. As the energy harvesting technology is still developing, this research presented an opportunity to apply the concept in the real environment.

\section{Acknowledgements}

This publication was supported by the program of the Polish Ministry of Science and Higher Education under the project DIALOG DIALOG 0019/DLG/2019/10 in the years 2019-2021.

\section{References}

[1] ORYNYCZ, O., SWIC, A. The effects of material's transport on various steps of production system on energetic efficiency of biodiesel production. Sustainability [online]. 2018, 10(8), 2736. eISSN 2071-1050. Available from: https://doi.org/10.3390/su10082736

[2] PARK, Y. S., LIM, S. H., EGILMEZ, G., SZMEREKOVSKY, J. Environmental efficiency assessment of US transport sector: A slack-based data envelopment analysis approach. Transportation Research Part D Transportation Environment [online]. 2018, 61(A), p. 152-164. ISSN 1361-9209. Available from: https://doi.org/10.1016/j.trd.2016.09.009

[3] LONGWIC, A., NIEOCZYM, A., KORDOS, P. Evaluation of the combustion process in a spark-ignition engine based on the unrepeatability of the maximum pressure. IOP Conference Series, Materials Science and Engineering [online]. 2018, 421(4), p. 1-9. ISSN 1757-8981, eISSN 1757-899X. Available from: https://doi.org/10.1088/1757-899X/421/4/042048

[4] TUCKI, K., MRUK, R., ORYNYCZ, O., GOLA, A. The effects of pressure and temperature on the process of auto-ignition and combustion of rape oil and its mixtures. Sustainability [online]. 2019, 11(12), 3451. eISSN 2071-1050. Available from: https://doi.org/10.3390/su11123451

[5] SZPICA, D. Investigating fuel dosage non-repeatability of low-pressure gas-phase injectors. Flow Measurement and Instrumentation [online]. 2018, 59, p. 147-156. ISSN 0955-5986. Available from: https://doi.org/10.1016/j. flowmeasinst.2017.12.009

[6] DANILOV, I., POPOVA, I., MOISEEV, Y. Analysis and validation of the dynamic method for diagnosing diesel engine connecting rod bearings. Transport Problems [online]. 2018,13(1), p. 123-133. eISSN 2300-861X. Available from: https://doi.org/10.21307/tp.2018.13.1.11

[7] STOECK, T., ABRAMEK, K. F. Application of the polynomial interpolation method for determining performance characteristics of a diesel engine. Metrology and Measurement Systems [online]. 2014, 21(1), p. 157-168. ISSN 0860-8229. Available from: https://doi.org/10.2478/mms-2014-0015 
[8] MIKULSKI, M., WIERZBICKI, S., SMIEJA, M., MATIJOSIUS, J. Effect of CNG in a fuel dose on the combustion process of a compression-ignition engine. Transport [online]. 2015, 30(2), p. 162-171. ISSN 1648-4142, eISSN 1648-3480. Available from: https://doi.org/10.3846/16484142.2015.1045938

[9] Makareviciene, V., MatiJOSIUS, J., PUKAlSkAS, S., VEGNERIS, R., KAZANCEVA, I., KAZANCEV, K. The exploitation and environmental characteristics of diesel fuel containing rapeseed butyl esters. Transport [online]. 2013, 28(2), p. 158-165. ISSN 1648-4142, eISSN 1648-3480. Available from: https://doi.org/10.3846/16484142.2013.801364

[10] SETIYO, M., WIDODO, E. M., ROSYIDI, M. I., PURNOMO, T. A., RAHARDJA, B. S., SURYANTORO, S. Economic values and $\mathrm{CO}_{2}$ Simulation on the application of LPG for public fleets in magelang, indonesia: executive data to support the clean city program. Periodyca Polytechnica Transportation Engineering [online]. 2020, 48(2), p. 159-172. ISSN 03037800, eISSN 1587-3811. Available from: https://doi.org/10.3311/PPtr.12841

[11] JEDLINSKI, L., JONAK, J. A disassembly-free method for evaluation of spiral bevel gear assembly. Mechanical Systems and Signal Processing [online]. 2017, 88, p. 399-412. ISSN 0888-3270. Available from: https://doi.org/10.1016/j. ymssp.2016.11.005

[12] SUN, W., YAO, B., ZENG, N., CHEN, B., HE, Y., CAO, X., HE, W. An intelligent gear fault diagnosis methodology using a complex wavelet enhanced convolutional neural network. Materials [online]. 2017, 10(7), 790. eISSN 1996-1944. Available from: https://doi.org/10.3390/ma10070790

[13] SAWALHI, N., RANDALL, R. B. Gear parameter identification in a wind turbine gearbox using vibration signals. Mechanical Systems and Signal Processing [online]. 2014, 42, p. 368-376. ISSN 0888-3270. Available from: https://doi. org/10.1016/j.ymssp.2013.08.017

[14] BOROWIEC, M., LITAK, G., SEN, A. K., HUNICZ, J., KOSZALKA, G., NIEWCZAS, A. Vibrations of a vehicle excited by real road profiles. Forschung im Ingenieurwesen [online]. 2010, 74, p. 99-109. ISSN 0015-7899, eISSN 1434-0860. Available from: https://doi.org/10.1007/s10010-010-0119-y

[15] KARIOJA, K., LAHDELMA, S., LITAK, G., AMBROZKIEWICZ, B. Extracting periodically repeating shocks in a gearbox from simultaneously occurring random vibration. In: 15th International Conference on Condition Monitoring and Machinery Failure Prevention Technologies CM/MFPT 2018: proceedings. 2018. p. 456-464.

[16] SOUALHI, A., MEDJAHER, K., ZERHOUNI, N. Bearing health monitoring based on Hilbert-Huang transform, support vector machine and regression. IEEE Transactions on Instrumentation and Measurement [online]. 2015, 64(1), p. 52-62. ISSN 0018-9456, eISSN 1557-9662. Available from: https://doi.org/10.1109/TIM.2014.2330494

[17] LITAK, G., BOROWIEC, M., HUNICZ, J., KOSZALKA, G., NIEWCZAS, A. Vibrations of a delivery car excited by railway track crossing. Chaos, Solitons and Fractals [online]. 2009, 42, p. 270-276. ISSN 0960-0779. Available from: https://doi.org/10.1016/j.chaos.2008.11.020

[18] MARICHAL, G. N., DEL CASTILLO, M. L., LOPEZ, J., PADRON, I., ARTES, M. An artificial intelligence approach for gears diagnostics in AUVs. Sensors [online]. 2016, 16(4), 529. eISSN 1424-8220. Available from: https://doi.org/10.3390/ s16040529

[19] BALYTSKYI, A., ABRAMEK, K. F., STOECK, T., OSIPOWICZ, T. Diagnostic of degradation of the lock seal ring by the loss of combustion engine working gases. Materials Science [online]. 2014, 50(1), p. 156-169. ISSN 1068-820X, eISSN 1573-885X. Available from: https://doi.org/10.1007/s11003-014-9704-9

[20] BRUMERCIK, F., LUKAC, M., MAJCHRAK, M., KRZYSIAK, Z., KRZYWONOS, L. Teeth geometry and contact pressure calculation of external cycloidal gears. Scientific Journal of Silesian University of Technology. Series Transport [online]. 2018, 101, p. 27-35. ISSN 0209-3324, eISSN 2450-1549. Available from: https://doi.org/10.20858/sjsutst.2018.101.3

[21] FIGLUS, T. A method for diagnosing gearboxes of means of transport using multi-stage filtering and entropy. Entropy [online]. 2019, 21(3), 441. eISSN 1099-4300. Available from: https://doi.org/10.3390/e21050441

[22] GHOLIKHANI, M., TAHAMI, S. A., KHALILI, M., DESSOUKY, S. Electromagnetic energy harvesting technology: key to sustainability in transportation systems. Sustainability [online]. 2019, 11(18), 4906. eISSN 2071-1050. Available from: https://doi.org/10.3390/su11184906

[23] ROSHANI, H., JAGTAP, P., DESSOUKY, S., MONTOYA, A., PAPAGIANNAKIS, A. T. Theoretical and experimental evaluation of two roadway piezoelectric-based energy harvesting prototypes. Journal of Materials in Civil Engineering [online]. 2017, 30, 04017264. ISSN 0899-1561, eISSN 1943-5533. Available from: https://doi.org/10.1061/ (ASCE)MT.1943-5533.0002112

[24] ZHANG, Y., GUO, K., WANG, D., CHEN, C., LI, X. Energy conversion mechanism and regenerative potential of vehicle suspensions. Energy [online]. 2017, 119, p. 961-970. ISSN 0360-5442. Available from: https://doi.org/10.1016/j. energy.2016.11.045

[25] ABDELKAREEM, M. A. A., XU, L., ALI, M. K. A., ElAGOUZ, A., MI, J.; GUO, S., LIU, Y., ZUO, L. Vibration energy harvesting in automotive suspension system: A detailed review. Applied Energy [online]. 2018, 229, p. 672-699. ISSN 0306-2619. Available from: https://doi.org/10.1016/j.apenergy.2018.08.030

[26] KURANC, A., SLOWIK, T., WASIlEWSKI, J., SZYSZLAK-BARGLOWICZ, J., STOMA, M., SARKAN, B. Emission of particulates and chosen gaseous exhausts components during a diesel engine starting process. In: 9th International Scientific Symposium on Farm Machinery and Process Management in Sustainable Agriculture: proceedings [online]. 
2017. p. 210-215. Available from: https://doi.org/10.24326/fmpmsa.2017.38

[27] LIZBETIN, J., STOPKA, O., KURENKOV, P. V. Declarations regarding the energy consumption and emissions of the greenhouse gases in the road freight transport sector. The Archives of Automotive Engineering - Archiwum Motoryzacji [online]. 2019, 83(1), p. 59-72. eISSN 2084-476X. Available from: https://doi.org/10.14669/AM.VOL83.ART4

[28] SKRUCANY, T., HARANTOVA, V., KENDRA, M., BARTA, D. Reducing energy consumption by passenger car with using of non-electrical hybrid drive technology. Advances in Science and Technology Research Jourmal [online]. 2018, 11(1), p. 166-172. ISSN 2299-8624. Available from: https://doi.org/10.12913/22998624/66505

[29] ZHAO, D. Waste thermal energy harvesting from a convection-driven thermo-acoustic-piezo system. Energy Conversion and Management [online]. 2013, 66, p. 87-97. ISSN 0196-8904. Available from: https://doi.org/10.1016/j. enconman.2012.09.025

[30] ITANI, K., DE BERNARDINIS, A., KHATIR; Z., JAMMAL, A. Comparative analysis of two hybrid energy storage systems used in a two front wheel driven electric vehicle during extreme start-up and regenerative braking operations. Energy Conversion and Management [online]. 2017, 144, p. 69-87. ISSN 0196-8904. Available from: https://doi.org/10.1016/j. enconman.2017.04.036

[31] WEI, C., JING, X. A comprehensive review on vibration energy harvesting: Modelling and realization. Renewable and Sustainable Energy Reviews [online]. 2017, 74, p. 1-18. ISSN 1364-0321. Available from: https://doi.org/10.1016/j. rser.2017.01.073

[32] WAlUBiTA, L.. SOHOUlande DJEBOU, D.. FARUK, A.. LEE, S.. DESSOUKY, S.. HU, X. Prospective of societal and environmental benefits of piezoelectric technology in road energy harvesting. Sustainability [online]. 2018, 10, 383. eISSN 2071-1050. Available from: https://doi.org/10.3390/su10020383

[33] PASCUAL-MUNOZ, P., CASTRO-FRESNO, D., SERRANO-BRAVO, P., ALONSO-ESTEBANEZ, A. Thermal and hydraulic analysis of multilayered asphalt pavements as active solar collectors. Applied Energy [online]. 2013, 111, p. 324-332. ISSN 0306-2619. Available from: https://doi.org/10.1016/j.apenergy.2013.05.013

[34] DATTA, U., DESSOUKY, S., PAPAGIANNAKIS, A. Harvesting thermoelectric energy from asphalt pavements. Transportation Research Record Journal of the Transportation Research Board [online]. 2017, 2628, p. 12-22. ISSN 0361-1981, eISSN 2169-4052. Available from: https://doi.org/10.3141/2628-02

[35] WANG, L., PARK, J.; ZHOU, W., ZUO, L. A large-scale on-road energy harvester from highway vibration. In: International Design Engineering Technical Conferences and Computers and Information in Engineering Conference ASME 2016: proceedings [online]. New York, NY, USA: American Society of Mechanical Engineers. 2016. ISBN 978-0-7918-5020-6. Available from: https://doi.org/10.1115/DETC2016-59562

[36] EFTHYMIOU, C., SANTAMOURIS, M., KOLOKOTSA, D., KORAS, A. Development and testing of photovoltaic pavement for heat island mitigation. Solar Energy [online]. 2016, 130, p. 148-160. ISSN 0038-092X. Available from: https://doi. org/10.1016/j.solener.2016.01.054

[37] JETTANASEN, C., SONGSUKTHAWAN, P., NGAOPITAKKUL, A. Development of micro-mobility based on piezoelectric energy harvesting for smart city applications. Sustainability [online]. 2020, 12(7), 2933. eISSN 2071-1050. Available from: https://doi.org/10.3390/su12072933

[38] SARKER, M. R., JULAI, S., SABRI, M. F., SAID, S. M., ISLAM, M. M., TAHIR, M. Review of piezoelectric energy harvesting system and application of optimization techniques to enhance the performance of the harvesting system. Sensors and Actuators A: Physical [online]. 2019, 300, p. 111634. ISSN 0924-4247. Available from: https://doi.org/10.1016/j. sna.2019.111634

[39] CHAlioris, C. E., KARAYANniS, C. G., ANGEli, G. M., PAPAdOPOUloS, N. A., FAVVATA, M. J., PROVIDAKIS, C. P. Applications of smart piezoelectric materials in a wireless admittance monitoring system (WiAMS) to Structures - Tests in RC elements. Case Studies in Construction Materials [online]. 2016, 5, p. 1-18. ISSN 2214-5095. Available from: https://doi.org/10.1016/j.cscm.2016.03.003

[40] MICEK, P., GRZYBEK, D. Wireless stress sensor based on piezoelectric energy harvesting for a rotating shaft. Sensors and Actuators A: Physical [online]. 2019, 301, 111744. ISSN 0924-4247. Available from: https://doi.org/10.1016/j. sna.2019.111744

[41] ERTURK, A., HOFFMANN, J., INMAN, D. J. A piezomagnetoelastic structure for broadband vibration energy harvesting. Applied Physics Letters [online]. 2009, 94, 254102. ISSN 0003-6951, eISSN 1077-3118. Available from: https://doi.org/10.1063/1.3159815

[42] VOCCA, H., NERI, I., TRAVASSO. F., GAMMAITONI, L. Kinetic energy harvesting with bistable oscillators. Applied Energy [online]. 2012, 97, p. 771-776. ISSN 0306-2619. Available from: https://doi.org/10.1016/j.apenergy.2011.12.087

[43] HUGUET, T., LALLART, M., BADEL, A. Orbit jump in bistable energy harvesters through buckling level modification. Mechanical Systems and Signal Processing [online]. 2019, 128, p. 202-215. ISSN 0888-3270. Available from: https://doi.org/10.1016/j.ymssp.2019.03.051

[44] HUGUET, T., BADEL, A., LALLART, M. Parametric analysis for optimized piezoelectric bistable vibration energy harvesters. Smart Materials and Structures [online]. 2019, 28, 115009. ISSN 0964-1726, eISSN 1361-665X. Available from: https://doi.org/10.1088/1361-665X/ab45c6 
[45] DEL-RIO-RUIZ, R., ECHEVARRIA, J. J., EGUILUZ, X., LOPEZ-GARDE, J.-M., LEGARDA, J. Experimental frequency tuning methodology of a cantilever piezoelectric harvester validated in a multimodal transportation. Electronics [online]. 2020, 9(1), 79. eISSN 2079-9292. Available from: https://doi.org/10.3390/electronics9010079

[46] YANG, T., WANG, T., LI, G., SHI, J., SUN, X. Vibration characteristics of compression ignition engines fueled with blended petro-diesel and Fischer-Tropsch diesel fuel from coal fuels. Energies [online]. 2018, 11(8), 2043. eISSN 1996-1073. Available from: https://doi.org/10.3390/en11082043

[47] TAGHIZADEH-ALISARAEI, A., GHOBADIAN, B., TAVAKOLI-HASHJIN, T., MOHTASEBI, S. S. Vibration analysis of a diesel engine using biodiesel and petrodiesel fuel blends. Fuel [online]. 2012, 102, p. 414-422. ISSN 0016-2361. Available from: https://doi.org/10.1016/j.fuel.2012.06.109

[48] HARNE, R. L., WANG, K. W. On the fundamental and superharmonic effects in bistable energy harvesting. Journal of Intelligent Material Systems and Structures [online]. 2013, 25(8), p. 937-950. ISSN 1045-389X, eISSN 1530-8138. Available from: https://doi.org/10.1177/1045389X13502856

[49] STANTON, S. C., MCGEHEE, C. C., MANN, B. P. Nonlinear dynamics for broadband energy harvesting: Investigation of a bistable piezoelectric inertial generator. Physica D [online]. 2010, 239(10), p. 640-653. ISSN 0167-2789. Available from: https://doi.org/10.1016/j.physd.2010.01.019

[50] MASANA, R., DAQAQ, M. F. Relative performance of a vibratory energy harvester in mono- and bi-stable potentials. Journal of Sound and Vibration [online]. 2011, 330, p. 6036-6052. ISSN 0022-460X. Available from: https://doi.org/10.1016/j.jsv.2011.07.031

[51] COTTONE, F., GAMMAITONI, L., VOCCA, H., FERRARI, M., FERRARI V. Piezoelectric buckled beams for random vibration energy harvesting. Smart Materials and Structures [online]. 2012, 21(3), 035021. ISSN 0964-1726, eISSN 1361-665X. Available from: https://doi.org/10.1088/0964-1726/21/3/035021

[52] COTTONE, F., BASSET, P., VOCCA, H., GAMMAITONI, L., BOUROUINA T. Bistable electromagnetic generator based on buckled beams for vibration energy harvesting. Journal of Intelligent Material Systems and Structures [online]. 2013, 25(3), p. 1-12. ISSN 1045-389X, eISSN 1530-8138. Available from: https://doi.org/10.1177/1045389x13508330

[53] LITAK, G., FRISWELL, M. I., ADHIKARI S. Magnetopiezoelastic energy harvesting driven by random excitations. Applied Physics Letters [online]. 2010, 96, 214103. ISSN 0003-6951, eISSN 1077-3118. Available from: https://doi.org/10.1063/1.3436553

[54] FRISWELl, M. I., ALI, S. F., ADHIKARI, S., LEES, A. W., BILGEN, O., LITAK, G. Nonlinear piezoelectric vibration energy harvesting from a vertical cantilever beam with tip mass. Journal of Intelligent Material Systems and Structures [online]. 2012, 23, p. 1505-1521. ISSN 1045-389X, eISSN 1530-8138. Available from: https://doi.org/10.1177/1045389X12455722

[55] COCCOLO, M., LITAK, G., SEOANE J., SANJUAN, M. A. F. Optimizing the electrical power in an energy harvesting system. International Journal of Bifurcation and Chaos [online]. 2015, 25, 1550171. ISSN 0218-1274, eISSN 1793-6551. Available from: https://doi.org/10.1142/S0218127415501710

[56] HUANG, D., ZHOU, S., LITAK, G. Theoretical analysis of multi-stable energy harvesters with high order stiffness terms. Communications in Nonlinear Science and Numerical Simulation [online]. 2019, 69, p. 270-286. ISSN 1007-5704. Available from: https://doi.org/10.1016/j.cnsns.2018.09.025

[57] AMBROZKIEWICZ, B., LITAK, G., WOLSZCZAK, P. Modelling of electromagnetic energy harvester with rotational pendulum using mechanical vibrations to scavenge electrical energy. Applied Sciences [online]. 2020, 10(2), 671. eISSN 2076-3417. Available from: https://doi.org/10.3390/app10020671 